\title{
Ethanol Extract of Antrodia camphorata Grown on Germinated Brown Rice Suppresses Inflammatory Responses in Mice with Acute DSS-Induced Colitis
}

\author{
Dong Ki Park ${ }^{1}$ and Hye-Jin Park ${ }^{2}$ \\ ${ }^{1}$ Cell Activation Research Institute, Konkuk University, 1 Hwayang-dong, Gwangjin-gu, Seoul 143-701, Republic of Korea \\ ${ }^{2}$ Department of Bioscience and Biotechnology, Konkuk University, Gwangjin-Gu, Achasan-rho 263, Seoul 143-701, Republic of Korea
}

Correspondence should be addressed to Hye-Jin Park; hyejinp@konkuk.ac.kr

Received 7 February 2013; Revised 10 April 2013; Accepted 22 April 2013

Academic Editor: Yew-Min Tzeng

Copyright (C) 2013 D. K. Park and H.-J. Park. This is an open access article distributed under the Creative Commons Attribution License, which permits unrestricted use, distribution, and reproduction in any medium, provided the original work is properly cited.

\begin{abstract}
The anti-inflammatory activity of Antrodia camphorata (AC) grown on germinated brown rice (CBR) extract was evaluated in vitro and in vivo. CBR suppressed the release of nitric oxide (NO) and prostaglandin (PG) E2 from lipopolysaccharide-(LPS-)stimulated RAW264.7 cells. CBR inhibited the level of inducible nitric oxide synthase (iNOS) and cyclooxygenase-(COX-)2 proteins, and it activated p38-MAPK, extracellular signal-related kinases (ERK), and NF- $\kappa$ B in LPS-stimulated RAW264.7 macrophages. LPSinduced tumor necrosis factor- $\alpha$ (TNF- $\alpha$ ) and interleukin-6 (IL-6) mRNA expression was reduced in CBR-treated RAW264.7 cells. In concert with in vitro data, CBR suppressed the levels of dextran-sulfate-sodium-(DSS-)induced iNOS and COX-2 proteins in the colon tissue. CBR treatment inhibited activated p38-MAPK, ERK, and NF- $\kappa$ B proteins in the colon tissue of DSS-induced mice. TNF- $\alpha$ and IL- 6 mRNA expression was reduced in DSS+CBR-treated mice. The disease activity index and histological scores were significantly lower in CBR-treated mice $(500 \mathrm{mg} / \mathrm{kg} /$ day) than in DSS-treated mice $(P<0.05$ versus DSS). This is the first report of anti-inflammatory activity of CBR in DSS-induced acute colitis. These results suggest that CBR is a promising, potential agent for preventing acute colitis through the inhibition of NF- $\kappa$ B signaling and its upstream signaling molecules, including MAPKs.
\end{abstract}

\section{Introduction}

Inflammatory bowel diseases (IBDs), including ulcerative colitis (UC) and Crohn's disease, are immunologically mediated chronic intestinal disorders. The incidence of IBDs increased considerably over the past half century in developed countries. The rapidity of these developments may be the result of exposure to nongenetic factors (as opposed to genetic factors) introduced through changes in the diet and lifestyle of genetically susceptible individuals, which can cause aberrant immune responses that lead to IBD. The modality of these diseases is commonly accompanied by severe intestinal inflammation, including abdominal pain, diarrhea, rectal bleeding, and weight loss [1-3]. Prolonged UC and chronic UC further develop into colorectal cancer at a high rate. In spite of substantial progress for treating UC, definitive therapies, which do not result in an eventual relapse, are not available to date, and limiting drug-induced toxicity is a huge challenge [4]. The abnormal mucosal immune and inflammatory responses in IBD are often characterized by induced production of proinflammatory cytokines, reactive oxygen, and nitrogen species and the activation of macrophages. An increase in the nuclear factor kappa B (NF- $\kappa$ B) signaling molecules has been detected in the mucosa of patients with IBD and in a murine colitis model. Inhibition of NF- $\kappa$ B activity, with a specific p65 antisense oligonucleotide, is effective in preventing experimental models of IBD, and it markedly downregulates proinflammatory cytokine production in intestinal macrophages in IBD patients $[5,6]$. This activated signaling leads to the production of proinflammatory cytokines (e.g., tumor necrosis factoralpha (TNF- $\alpha$ ), interleukin-1 $\beta$ (IL-1 $\beta)$, IL-6, IL-8, and IL12) and the expression of inflammatory-related proteins (e.g., cyclooxygenase-2 (COX-2) and inducible nitric oxide synthase (iNOS)). Therefore, the overexpression of proinflammatory cytokines and inflammatory-related proteins 
contributes to the inflammatory cascade in the pathological progression of colitis [7].

Recently, natural products and their derived compounds have been proposed as novel drug candidates owing to their broad spectra of therapeutic effects with low toxicity. Antrodia camphorata (AC) is an indigenous and rare mushroom of the Polyporaceae family that grows only on the inner heart rot of the native Taiwanese tree Cinnamomum kanehirai Hay (Lauraceae). AC is used in traditional Chinese medicine for treating food and drug poisoning, diarrhea, abdominal pain, hypertension, pruritis (skin itch), and liver dysfunction $[1,8-10]$. Recent studies have highlighted various biological functions of AC, including antioxidant, anti-inflammatory, antihepatitis, antitumor, and immunomodulatory properties $[1,11,12]$. However, obtaining massive amounts of AC in nature is not easy because it is a parasitic fungus that only grows in the inner cavity of Cinnamomum kanehirai Hay (Lauraceae; Bull camphor tree) at an altitude of 200$2000 \mathrm{~m}$ in Taiwan. To solve the low production yield of AC, our study group developed novel culture methods by inoculating $\mathrm{AC}$ mycelia on germinated brown rice (CBR) that are rich in nutrients and biologically active compounds. Recently, our group identified various anticancer activities of CBR against B16F10 cancer cells [13]. Despite the reported beneficial effects of AC, its pharmacological actions against inflammatory bowel disease have not been documented. In this study, we explored the ability of CBR to regulate inflammatory responses and the underlying mechanism by using macrophage-mediated inflammatory conditions and DSS-induced acute colitis.

\section{Materials and Methods}

2.1. Preparation of CBR Extract. A. camphorata grown on germinated brown rice (CBR) was provided by Cell Activation Research Institute (CARI, Seoul, Republic of Korea). Germinated brown rice was used as culture media for A. camphorata mycelia. A. camphorata mycelia was inoculated onto the germinated brown rice and cultured for 8 weeks at 20$25^{\circ} \mathrm{C}$. Dried 8-week CBR was ground into a fine powder using a grinder. Powder $(2 \mathrm{~kg})$ was extracted with $80 \%$ ethanol $(\mathrm{EtOH})$ at $20-25^{\circ} \mathrm{C}$. After filtration, the ethanol extracts were dried with a rotary evaporator under vacuum and the extract was stored at $-20^{\circ} \mathrm{C}$. Authenticated voucher specimens of CBR (Kucari 1101) are deposited in the Herbarium at College of Bioscience and Biotechnology, Konkuk University, Seoul, Republic of Korea.

2.2. Cell Culture. RAW 264.7 macrophages were purchased from the American Type Culture Collection (ATCC; Rockville, MD, USA) and cultured in regular media consisting of Dulbecco's modified Eagle's medium (DMEM; Invitrogen, Carlsbad, CA, USA), $10 \%$ fetal bovine serum (FBS; Invitrogen), and $100 \mathrm{U} / \mathrm{mL}$ penicillin-streptomycin (Sigma).

2.3. NO, PGE 2 , and TNF- $\alpha$ Assays. Nitrite concentrations in RAW 264.7 cell culture media were measured using the
Griess reaction as described previously [14]. $\mathrm{PGE}_{2}$ levels were measured using enzyme-linked immunosorbent kits (Cayman Chemical Co., Ann Arbor, MI, USA) as described previously [15]. Enzyme-linked immunosorbent assay (ELISA) was performed according to the manufacturer's protocol for measuring the level of TNF- $\alpha$ (Pierce Biotechnology, Rockford, IL, USA). For these assays, cells $\left(5 \times 10^{4}\right.$ cells $\left./ \mathrm{mL}\right)$ were pretreated in the presence or absence of CBR or AC extract for $1 \mathrm{~h}$ before lipopolysaccharide (LPS; $1 \mu \mathrm{g} / \mathrm{mL}$, Sigma) stimulation for 20 hours.

2.4. Isolation of Nuclear Extracts. RAW264.7 macrophages were pretreated in the presence or absence of CBR extract ( 0 , 50 , and $100 \mu \mathrm{g} / \mathrm{mL}$ ) for $1 \mathrm{~h}$ before stimulation with $1 \mu \mathrm{g} / \mathrm{mL}$ LPS. Nuclei were isolated and nuclear proteins were extracted using the Nuclear Extraction Kit from Panomics (Panomics Inc., Redwood City, CA, USA).

2.5. Western Blotting. Cell extracts and colon tissues were separated on a $10 \%$ SDS-PAGE gel, transferred to a sheet of nitrocellulose membrane (Millipore; Billerica, MA, USA), and blocked in $5 \%$ nonfat milk for $1 \mathrm{~h}$. Samples were probed with the following primary antibodies: iNOS, COX-2, NF$\kappa \mathrm{B}$, phospho-p38, p38, phosphoextracellular signal-related kinases (ERK1/2), ERK1/2, and $\beta$-actin (all from Santa Cruz, CA, USA). The secondary antibodies used were horseradish peroxidase-conjugated goat antirabbit or anti-mouse antibodies (Pierce, Rockford, IL, USA). An enhanced chemiluminescence reaction was performed using a SuperSignal West Femto Enhancer Kit (Pierce), and the positive bands were detected on an X-ray film.

2.6. Quantitative Real-Time Polymerase Chain Reaction. RAW 264.7 macrophages were treated with CBR extract $(0,50$, and $100 \mu \mathrm{g} / \mathrm{mL})$ followed by LPS stimulation. Total RNA was isolated using an RNA isolation kit according to the manufacturer's instructions (Toyobo, Japan) and then reverse-transcribed. Thereafter, RT-PCR was performed using an ABI7500 thermal cycler (Applied Biosystems, Foster City, CA, USA) with a set of primers corresponding to iNOS (QT00100275), TNF- $\alpha$ (QT00104006), and GAPDH (QT01658692) (all from Qiagen, Valencia, CA, USA). Relative iNOS and TNF- $\alpha$ mRNA levels were normalized with GAPDH and calculated using the $2^{\Delta \Delta} \mathrm{Ct}$ method.

2.7. Animal Experiment. C57BL/6 mice (6 weeks old, female) were purchased from the DaeHan Experimental Animal Center (Eumsung, Korea). Mice were acclimatized under controlled, specific pathogen-free (SPF) conditions for 1 week prior to the experiment. All mice were housed in individual cages and fed standard laboratory chow in an animal room with $12 \mathrm{~h}$ light/dark cycles. All animals were handled following the guidelines of the Institutional Animal Care and Use Committee (IACUC) at Konkuk University (Seoul, Republic of Korea). The authorization code number from IACUC was ku11069. 
TABLE 1: Disease activity index (DAI) scoring. The sum of scores for the DAI category.

\begin{tabular}{|c|c|c|c|}
\hline \multirow{2}{*}{ Score } & \multicolumn{3}{|c|}{ Symptom } \\
\hline & Weight loss & Stool consistency & Bleeding \\
\hline 0 & no & Normal stools & Normal \\
\hline 1 & $1 \%-5 \%$ & & \\
\hline 2 & $6 \%-10 \%$ & Loose stools & Slight bleeding \\
\hline 3 & $11 \%-20 \%$ & & \\
\hline 4 & $\sim 20 \%$ & Diarrhea & Gross bleeding \\
\hline
\end{tabular}

2.8. Experimental Protocol. Acute colitis was induced in C57BL6/N mice by adding DSS (MP Biologicals, USA) to drinking tap water $(3.5 \% \mathrm{v} / \mathrm{v})$ for 9 days, as previously described $[1,3,16]$. Mice were randomly assigned to 4 groups ( $n>5$ per group). The groups were as follows: Group 1, normal mice administered with drinking water and vehicle for 11 days; Group 2, mice pretreated with a vehicle for 2 days and then coadministered with a vehicle and 3.5\% DSS for 9 days; Group 3, mice pretreated with CBR for 2 days and then coadministered with 3.5\% DSS and CBR EtOH extract $(200 \mathrm{mg} / \mathrm{kg} /$ day) for 9 days; and Group 4, mice pretreated with CBR for 2 days and then coadministered with 3.5\% DSS and CBR EtOH extract ( $500 \mathrm{mg} / \mathrm{kg} /$ day) for 9 days.

2.9. Evaluation of the Disease Activity Index (DAI). The DAI was used for evaluating the grade and extent of intestinal inflammation [3]. Body weight, stool consistency, and blood in the stool were monitored daily for determination of the DAI. Each score was defined as follows: for body weight loss, $0=$ none, $1=1-5 \%, 2=6 \%-10 \%, 3=11 \%-20 \%$, and $4=>20 \%$; for diarrhea, $0=$ normal, $2=$ loose stools, and $4=$ watery diarrhea; and for blood, $0=$ normal, $2=$ slight bleeding, and $4=$ gross bleeding. The DAI score ranged from 0 to 12 (total score) (Table 1).

2.10. H↔E Staining and Assessment of Histological Score. Colon tissue sections were stained with hematoxylin and eosin (H\&E) as previously described [3]. Stained sections were examined by light microscopy (Nikon Co., Japan) (magnifications: 100x and 200x). The histological scoring system was used for evaluating the degree of colitis with $\mathrm{H} \& \mathrm{E}$ images following a previously published scoring system [3]. The scoring system was as follows: $0=$ no change from normal tissue; 1 = low level of inflammation with scattered infiltrating mononuclear cells (1-2 foci); 2 = moderate inflammation with multiple foci; $3=$ a high level of inflammation with increased vascular density and marked wall thickening; and $4=$ severe inflammation with transmural leukocyte infiltration and a loss of goblet cells.

2.11. Immunohistochemistry. The distal colon was dissected and a longitudinal section ( $1.5 \mathrm{~cm}$ from the anal verge) was prepared. The immunohistochemical staining of the colon section $(4 \mu \mathrm{m})$ was performed using the ImmunoCruz system (Santa Cruz, CA, USA). Tissue sections were incubated with antibodies against NF- $\kappa$ B p65 (Santa Cruz; 1:50). Sections were developed by using the $\mathrm{DAB}$ chromogen kit (Vector laboratories, Burlingame, CA, USA) and counterstained with $1 \%$ methyl green for $1 \mathrm{~min}$. The sections were observed by microscopy (Nikon Co., Japan).

2.12. Statistical Analysis. Data were expressed as means \pm standard error of the mean. A one-way ANOVA was used for assessing significance between the control group and sample treated groups. Two-way repeated-measure ANOVAs were used to analyze the data at different time points. Statistical analysis was performed using SPSS, version 12 (SPSS Inc., Chicago, IL, USA).

\section{Results}

3.1. CBR EtOH Extract Inhibited $\mathrm{NO}$ and $\mathrm{PGE}_{2}$ Production and Proinflammatory Cytokine mRNA Expression in LPSStimulated RAW264.7 Cells. In an effort to investigate the anti-inflammatory activity of $A$. camphorata grown on germinated brown rice (CBR) and A. camphorata (AC), we first confirmed whether they inhibit NO production in activated macrophages. LPS $(1 \mu \mathrm{g} / \mathrm{mL})$ was used as a positive control for macrophage activation (Figure 1(a)). CBR significantly inhibited NO production compared to AC at $200 \mu \mathrm{g} / \mathrm{mL}(P<$ 0.01 versus AC). The $50 \%$ inhibitory concentrations (IC50) of NO production by CBR and AC were $312.02 \pm 16.67 \mu \mathrm{g} / \mathrm{mL}$ and $525.20 \pm 15.4 \mu \mathrm{g} / \mathrm{mL}$, respectively (Figure $1(\mathrm{a})$ ).

Therefore, we chose CBR EtOH extract as a test sample for this study. CBR treatment blocked the production of $\mathrm{PGE}_{2}$ in LPS-stimulated RAW264.7 cells in a dose-dependent manner (Figure 1(b)). To understand the molecular inhibitory mechanism of $\mathrm{CBR}$ on $\mathrm{NO}$ and $\mathrm{PGE}_{2}$ production, we evaluated iNOS and COX-2 protein expression. Protein levels of iNOS and COX- 2 were significantly decreased at $100 \mu \mathrm{L} / \mathrm{mL}$ of CBR treatment (Figure 1(c)). In addition, LPS-induced IL-6 and TNF- $\alpha$ mRNA levels were significantly inhibited by CBR treatment $(100 \mu \mathrm{L} / \mathrm{mL})$ (Figure 2). CBR (50 and $100 \mu \mathrm{g} / \mathrm{mL}$ ) significantly reduced macrophage TNF- $\alpha$ secretion from 44.3 $\pm 2.58 \mathrm{ng} / \mathrm{mL}$ to $27.4 \pm 1.70 \mathrm{ng} / \mathrm{mL}$ and $19.0 \pm 0.35 \mathrm{ng} / \mathrm{mL}$, respectively $\left({ }^{* * *} P<0.001\right.$ versus LPS-stimulated control).

3.2. CBR EtOH Extract Inhibited NF- $\kappa B$ Expression in LPSStimulated RAW264.7 Cells. Figure 1 shows that CBR EtOH extract inhibition could be due to the blockade of transcriptional activation induced by inflammation-regulating signaling molecules and transcription factors such as MAPK and NF- $\kappa \mathrm{B}$ [7]. First, we determined whether CBR inhibited phosphorylation of MAPK. CBR extract decreased the expression of phosphorylated ERK and p38-MAPK in a dose-dependent manner in LPS-induced RAW264.7 cells (Figure 3(a)), respectively. Here, we investigated whether CBR extract could suppress the activation of NF- $\kappa \mathrm{B}$, using western blot analysis. NF- $\kappa$ B activation is essential for the inflammatory response in RAW264.7 cells. Since the hyperphosphorylation of $\mathrm{I} \kappa \mathrm{B}$ and its subsequent degradation is an essential step in NF- $\kappa \mathrm{B}$ activation by various stimuli [5]. Equivalent proteins from nucleus were used to check whether the NF- $\kappa$ B activation was affected by CBR extract 


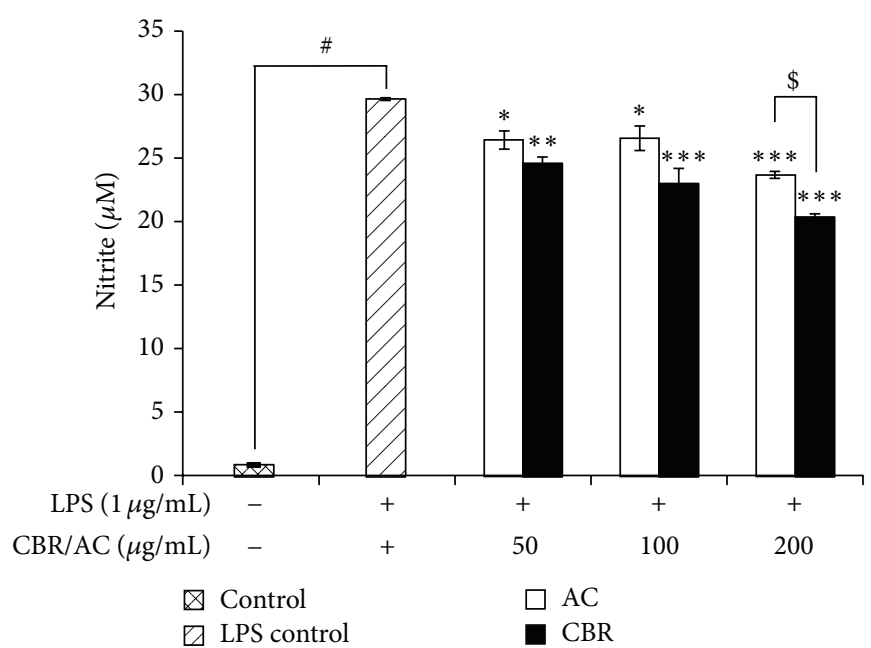

(a)

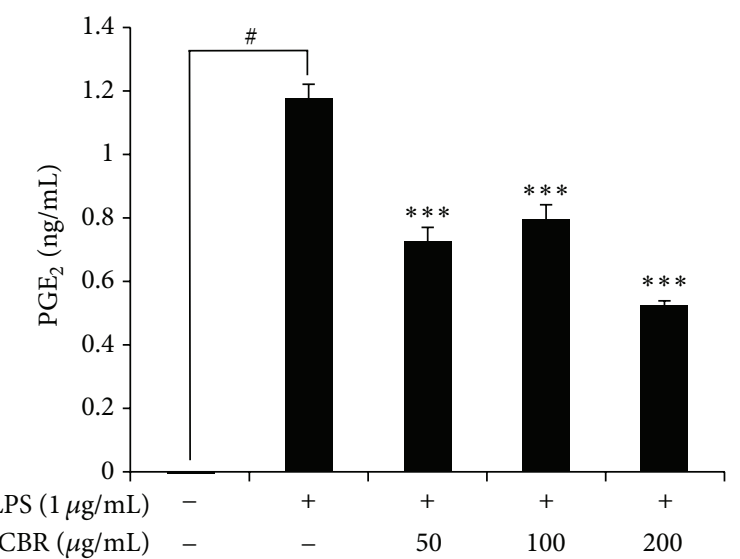

(b)

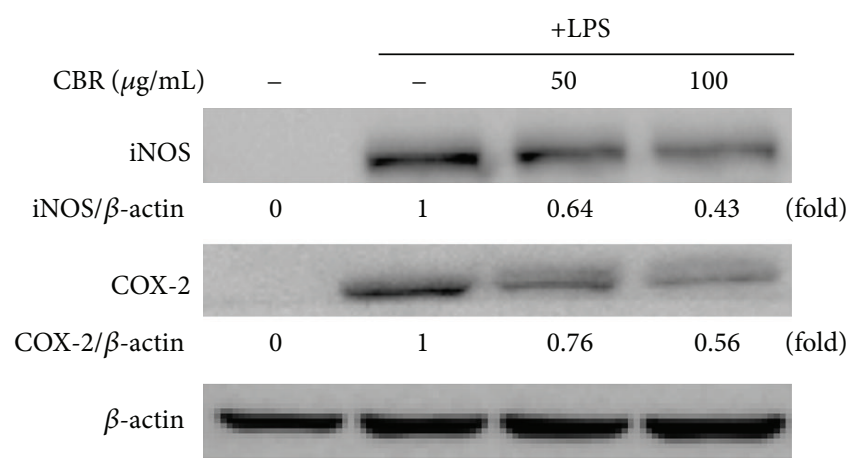

(c)

FIGURE 1: Effect of the CBR extract on $\mathrm{NO}$ and $\mathrm{PGE}_{2}$ production and iNOS and COX-2 protein expression levels in LPS-stimulated RAW264.7 macrophages. Cells were incubated for $20 \mathrm{~h}$ with $1 \mu \mathrm{g} / \mathrm{mL}$ of LPS in the absence or presence of the CBR or AC extract. The CBR extract was added $1 \mathrm{~h}$ prior to incubation with LPS. $(\mathrm{a}, \mathrm{b})$ Nitrite and $\mathrm{PGE}_{2}$ production in the medium was determined using the Griess reagent and PGE EIA kit. (c) Protein expression of iNOS and COX-2 was analyzed by western blot analysis and quantified by densitometric analysis. Data show the mean \pm standard error (S.E.) of 3 independent experiments. A one-way ANOVA was used for comparisons of multiple group means followed by Dunnett's $t$-test $\left({ }^{\#} P<0.001\right.$ versus control; ${ }^{*} P<0.01,{ }^{* *} P<0.05$, and ${ }^{* * *} P<0.001$ versus LPS-stimulated control; ${ }^{\$} P<0.05$ versus $A C)$.

and the cytosolic proteins were used to determine the degradation of $\mathrm{I} \kappa \mathrm{B}$. We found that CBR extract strongly inhibited translocation of NF- $\kappa$ B p65 subunit (Figure $3(\mathrm{~b})$ ) as well as inhibited $\mathrm{I} \kappa \mathrm{B} \alpha$ phosphorylation in a dose-dependent manner (Figure 3(b)). Therefore, these results strongly suggest that CBR extract can suppress the production of inflammatory mediators and proinflammatory cytokines by suppressing $\mathrm{NF}-\kappa \mathrm{B}$-mediated transcriptional activation.

\subsection{CBR EtOH Extract Attenuated DSS-Induced Acute Colitis} Symptoms. Anti-inflammatory activities of the CBR EtOH extract were also evaluated using mice with DSS-induced acute colitis, which exhibit similar symptoms to the acute phase of human ulcerative colitis. To study the prophylactic effect of the $\mathrm{CBR}$ EtOH extract, mice were administered with CBR $(500 \mathrm{mg} / \mathrm{kg}$ ) for 2 days, followed by administration of $3.5 \%$ DSS (Figure $4(\mathrm{a})$ ). It has been reported that the length of the colon is inversely linked to the severity of DSS-induced acute colitis. We found that the colon of CBR EtOH extract- (200 and $500 \mathrm{mg} / \mathrm{kg} /$ day) administered mice had been significantly longer than that of the DSStreated group (Figure 4(b)). Changes in the body weight were checked daily during the experiment. Marked weight reductions were observed in the DSS groups, whereas the CBR EtOH extract $(500 \mathrm{mg} / \mathrm{kg} /$ day) significantly attenuated DSS-induced weight reductions at 7-10 days $(P<0.05)$ (Figure 4(c)). Mortality was only observed in DSS-treated group on day 10 (Figure $4(\mathrm{~d})$ ). In order to determine if CBR EtOH extract can attenuate acute colitis symptoms, we quantitatively scored macroscopic clinical symptoms, using the disease activity index (DAI) (e.g., body weight loss, diarrhea, and gross bleeding) (Table 1). An induction in DAI was observed in DSS-treated mice (Figure 5). The DAI was significantly lower in CBR + DSS-treated mice compared with DSS-treated mice on days 8,9 , and $10(P<0.05)$. The colitis 


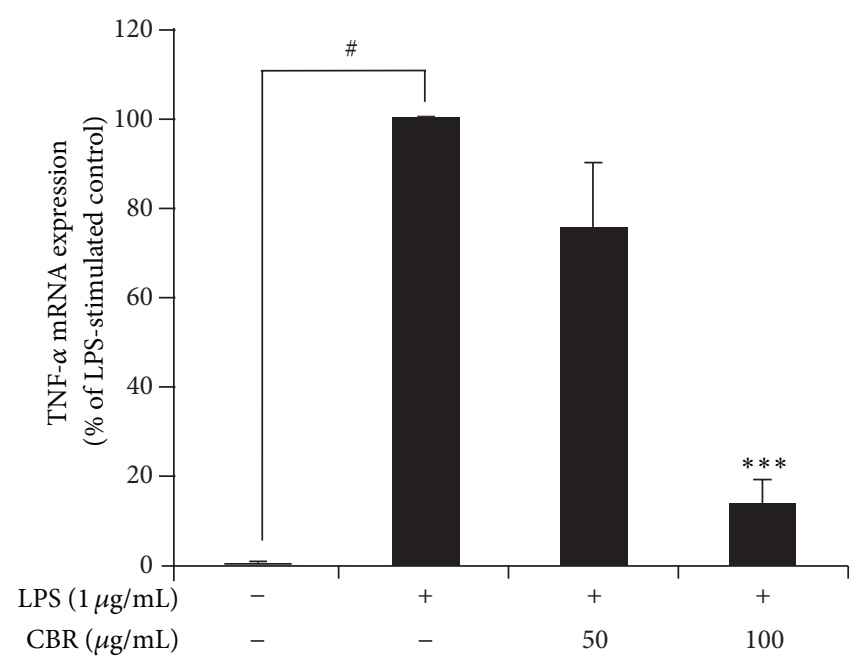

(a)

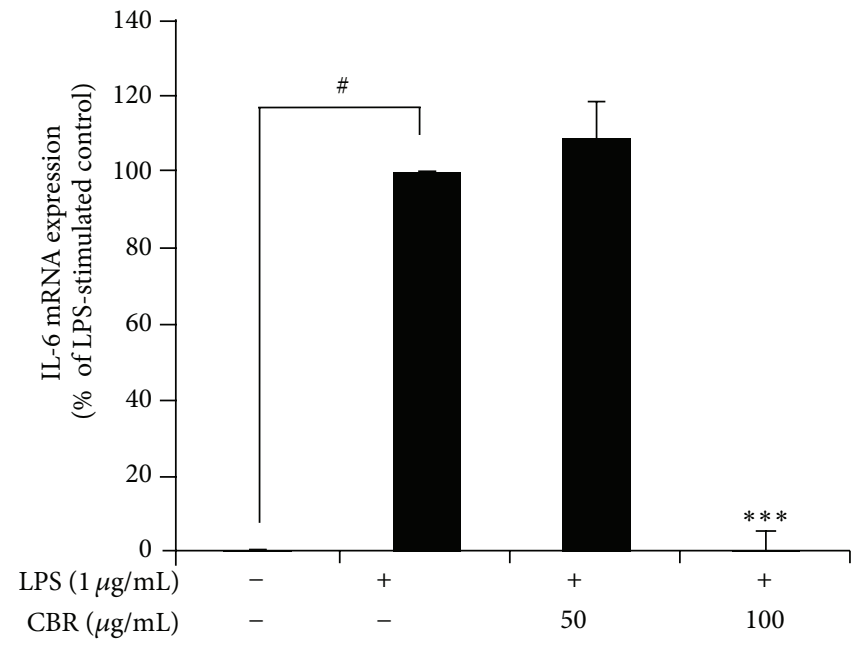

(b)

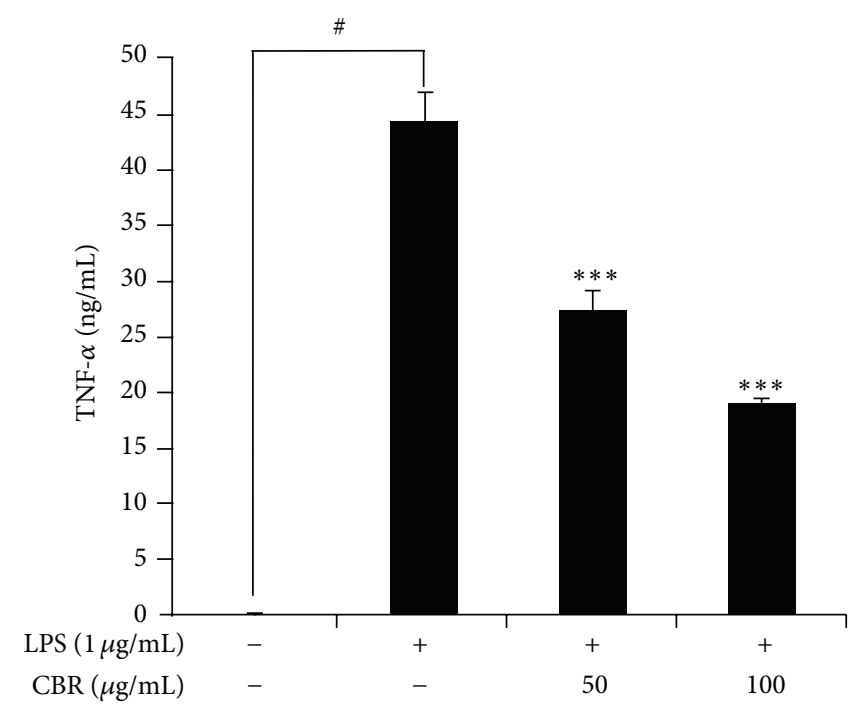

(c)

FIGURE 2: Effect of CBR extract on the level of proinflammatory cytokines in LPS-stimulated RAW264.7 macrophages. (a, b) Cells were incubated for $5 \mathrm{~h}$ with $1 \mu \mathrm{g} / \mathrm{mL}$ of LPS in the absence or presence of the CBR extract. The CBR extract was added $1 \mathrm{~h}$ prior to incubation with LPS. Levels of TNF- $\alpha$ and IL-6 mRNA in LPS-stimulated RAW264.7 cells were analyzed by real-time polymerase chain reaction (RTPCR) and determined by quantitative $\Delta \Delta \mathrm{C}_{\mathrm{T}}$ RT-PCR by using GAPDH mRNA as the internal control. Data represent the mean \pm S.E. of 3 independent experiments. A one-way ANOVA was used for comparisons of multiple group means followed by Dunnett's $t$-test $\left({ }^{\#} P<0.001\right.$ versus control; ${ }^{*} P<0.01,{ }^{* *} P<0.05$, and ${ }^{* * *} P<0.001$ versus LPS-stimulated control).

seen in mice fed CBR EtOH extract (500 mg/kg/day) was less severe and extensive (Figure 5).

3.4. CBR Extract Decreased Histological Changes. We examined the architecture of colonic structure microscopically, using hematoxylin and eosin (H\&E) staining method. Mice with DSS-induced acute colitis showed edema, distorted epithelial barrier, significant loss of crypts and goblet cells, and marked infiltration of leukocytes into the mucosa and submucosa, compared to control group. CBR extract group showed relatively well-preserved mucosal and crypt structure and less infiltration of inflammatory cells in the colonic tissues compared to the DSS-treated group (Figure 6(a)). These changes paralleled differences in histological colitis scores. There histological changes were assessed by grading scores as described in Section 2. Mean histopathology scores were lower in the group fed with CBR EtOH extract $(3.3 \pm 0.3)$ than those in the DSS-treated group (1.3 \pm 0.3 ) (Figure 6(b)).

3.5. CBR EtOH Extract Treatment Attenuated iNOS, COX-2, and Proinflammatory Cytokine Expression in the Colon Tissue of Mice with DSS-Induced Colitis. We examined whether the inhibitory mechanism exhibited by the CBR EtOH extract could also be observed in the DSS-induced colitis model. In 


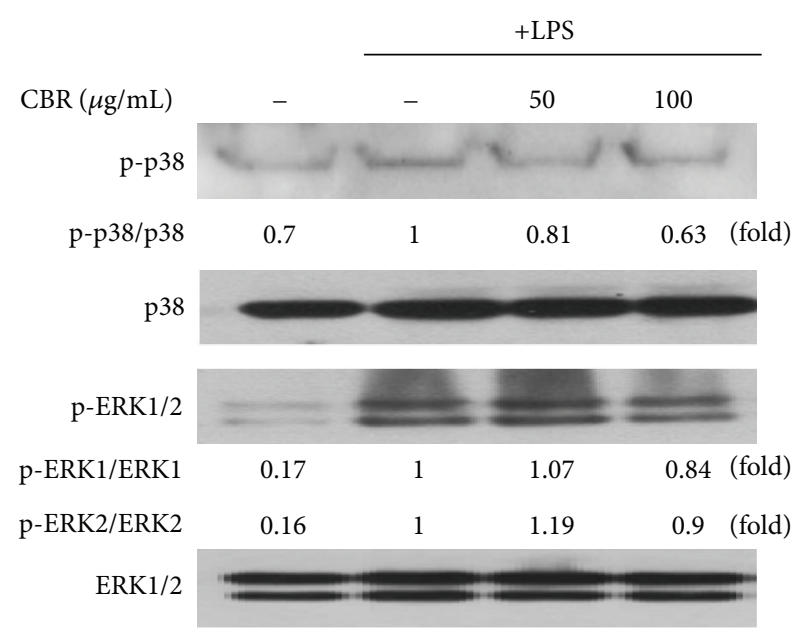

(a)

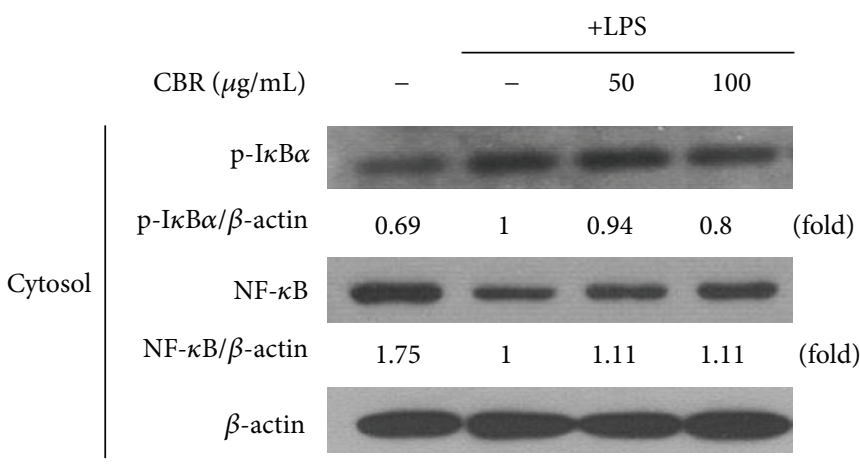

$\mathrm{NF}-\kappa \mathrm{B}$

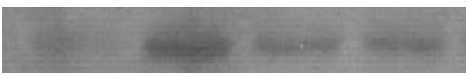

(b)

Figure 3: Effect of the CBR extract on MAPK and NF- $\kappa$ B expression in LPS-stimulated RAW264.7 cells. (a, b) Cells were incubated for $30 \mathrm{~min}$ with $1 \mu \mathrm{g} / \mathrm{mL}$ of LPS in the absence or presence of the CBR extract. The CBR extract was added $1 \mathrm{~h}$ prior to incubation with LPS. Protein expression of MAPK and NF- $\kappa$ B was analyzed by western blot analysis and quantified by densitometric analysis.

agreement with the in vitro data, reduced levels of iNOS and COX-2 proteins were observed in the CBR EtOH extracttreated group compared to the DSS-treated group (Figure 7). Colonic injury by DSS administration resulted from an increase of proinflammatory cytokine TNF- $\alpha$ [17]. It has been shown that selective blockade of TNF- $\alpha$ and IL- 6 significantly decreases the severity of colitis and neutrophil/macrophage migration [18]. Next, we measured the levels of TNF- $\alpha$ and IL-6 mRNA in colonic tissue. The CBR extract significantly blocked TNF- $\alpha$ mRNA expression in the colonic tissues of mice with DSS-induced acute colitis (Figure 7).

3.6. CBR EtOH Extract Prevents Colonic MAPKs and NF$\kappa B$ Activation in the Colon Tissue after DSS Administration. Activated MAPKs and transcriptional factor NF- $\kappa$ B primarily contribute to the major proinflammatory signaling pathways involved in colitis. Phosphorylation of ERK and p38-MAPK was upregulated in the colon tissue of experimental colitis. Figure 3 shows that the CBR EtOH extract inhibited the phosphorylation of ERK and p38-MAPK, as well as the translocation of NF- $\kappa$ B. Whether such inhibition by the CBR $\mathrm{EtOH}$ extract could also be observed in an in vivo disease model was assessed using a DSS-induced colitis model. DSS stimulated activation of p38 and ERK, whereas DSS-induced p38 and ERK phosphorylation diminished to $25 \%$ and $45 \%$, respectively, in the colonic tissue after CBR extract administration (Figure 8(a)). Low levels of NF- $\kappa$ B p65 were detected in the naive mouse colon; however, DSS induced the protein level of $\mathrm{p} 65 \mathrm{NF}-\kappa \mathrm{B}$ in the colonic tissue after 7 days (Figures $8(\mathrm{~b})$ and $8(\mathrm{c})$ ). Immunohistochemistry results also showed that the protein expression of NF- $\kappa \mathrm{B}$ p65 in DSS group was distinctly elevated compared with control group $(P<0.01$, Figure 8(c)), while the pretreatment with CBR EtOH extract $(500 \mathrm{mg} / \mathrm{kg}$, p.o.) significantly inhibited the $\mathrm{p} 65 \mathrm{NF}-\kappa \mathrm{B}$ in the mouse colon tissue. Thus, this result strongly suggests that suppression of activated MAPKs (e.g., p38, ERK) and NF$\kappa \mathrm{B}$ activation seems to be the key mechanism through which $\mathrm{CBR} \mathrm{EtOH}$ extract modulates intestinal inflammation.

\section{Discussion}

Antrodia camphorata (AC) is a traditional medicine in Taiwan and China for treating liver dysfunction, food and drug poisoning, diarrhea, abdominal pain, hypertension, and inflammation $[1,8-10]$. In spite of its usage as a traditional medicine, there are no papers on anti-inflammatory activities of AC against inflammatory bowel diseases (IBDs), including Crohn's disease (CD) and ulcerative colitis (UC). The aim of this study is to demonstrate anti-IBD activities of AC on germinated brown rice (CBR) and its anti-inflammatory mechanism of action.

Therefore, we first checked the anti-inflammatory effects of the CBR extract on LPS-stimulated RAW264.7 cells. LPSstimulated macrophages release proinflammatory mediators (e.g., $\mathrm{NO}$ and $\mathrm{PGE}_{2}$ ) and proinflammatory cytokines such as TNF- $\alpha$ and IL-6 $[8,19]$. Overproduction of NO by macrophages provokes various inflammatory diseases [20]. CBR significantly inhibited $\mathrm{NO}$ and $\mathrm{PGE}_{2}$ production from LPS-induced macrophages with no cytotoxicity (Figure 1). The suppressive effect of CBR extract occurr at the translational level. CBR decreased the level of iNOS and COX-2 protein in LPS-induced macrophages (Figure 1(d)). CBR also suppressed mRNA expression in TNF- $\alpha$ and IL-6 (Figure 2). In order to elucidate the probable mechanisms through which the CBR extract ameliorates these inflammatory responses in experimental colitis, changes in NF- $\kappa \mathrm{B}$ and its upstream signaling pathway, and the relative expressions of serial signaling molecules, we performed western blot analysis. Three major groups of MAPKs include the ERK, the c-Jun $\mathrm{NH} 2$-terminal kinases, and $\mathrm{p} 38$-MAPKs, which are activated 


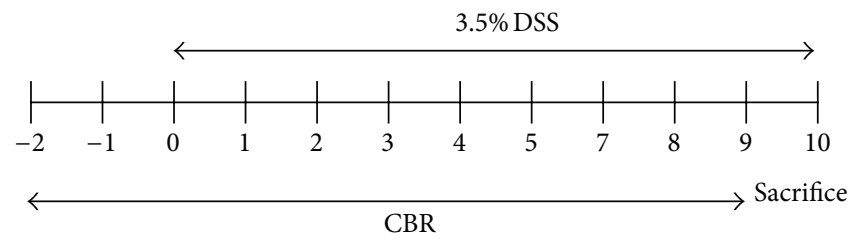

(a)
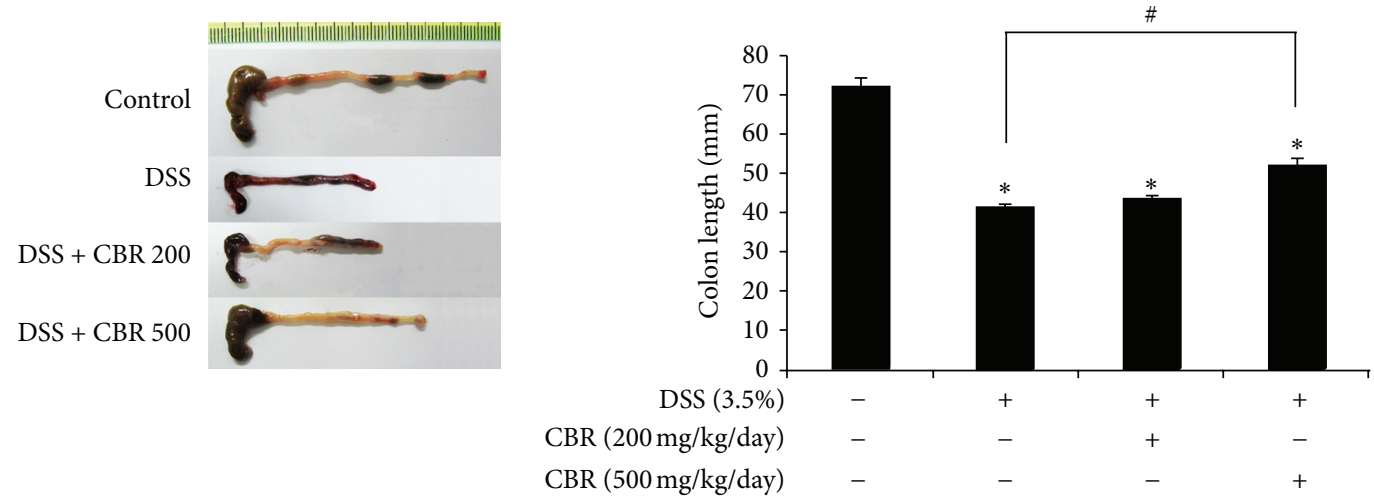

(b)

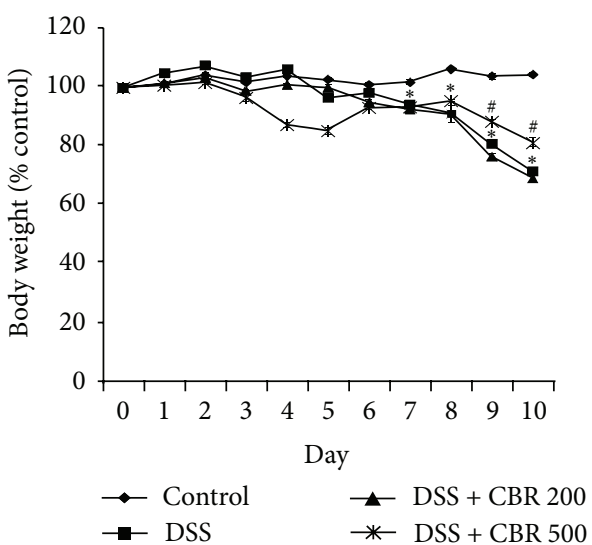

(c)

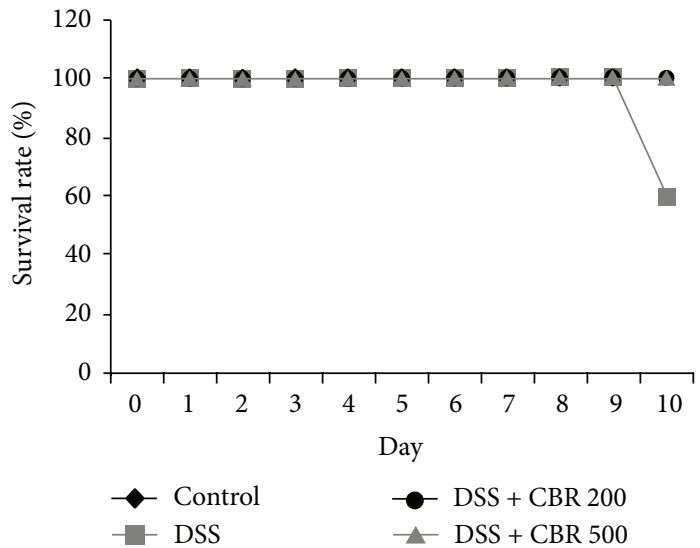

(d)

FIGURE 4: The CBR extract attenuated the severity of DSS-induced acute colitis. (a) Scheme of the experimental design. (b) Colons from each group were collected at day 10 after DSS instillation. Macroscopic images of the colons are shown (left panel). Colon length of each mouse was measured (right panel). (c) Changes in body weight were measured. Body weight was presented as the percentage of the initial weight (at day 0$)$. Data are expressed as the mean \pm S.E. ( $n=6$ per group) $\left({ }^{*} P<0.05\right.$ versus control; ${ }^{\#} P<0.05$ versus DSS; two-way ANOVA followed by a post hoc analysis). (d) Difference in survival rate. This experiment was repeated twice, and similar results were obtained. DSS dextran sulfate sodium; CBR: Antrodia camphorata (AC) grown on germinated brown rice.

by phosphorylation. They are the upstream enzymes for NF$\kappa \mathrm{B}$. MAPK cascades propagate signals, which change gene expressions that control diverse functions (e.g., inflammatory responses in various cells like macrophages, monocytes, and epithelial cells) [21-23]. NF- $\kappa \mathrm{B}$ can be activated by various stimuli (e.g., proinflammatory cytokines, microbes and microbial products, and oxidative stress) that signal its activation through the catalytic $\operatorname{I} \kappa \mathrm{B}$ kinase $\beta(\operatorname{IKK} \beta)$ [6]. IKK $\beta$ phosphorylates NF- $\kappa \mathrm{B}$-bound I $\kappa$ Bs in the cytoplasm and targets their degradation, thereby leading to the subsequent release of NF- $\kappa \mathrm{B}$ dimmers. Subsequently, these NF$\kappa \mathrm{B}$ dimmers translocate from the cytoplasm to the nucleus and activate the transcription of multiple $\kappa \mathrm{B}$-dependent target genes (e.g., TNF- $\alpha$, IL- $1 \alpha$, and IL-6), intercellular adhesion molecules, COX-2, and iNOS [24, 25]. We found that $\mathrm{CBR}$ suppressed ERK and p38 phosphorylation, NF- $\kappa \mathrm{B}$ translocation, and I- $\kappa$ B phosphorylation in LPS-stimulated RAW264.7 cells (Figure 3).

Finally, the anti-inflammatory activity of CBR was examined using the DSS-induced colitis model. DSS is administered to mice to mimic UC symptoms by disrupting the epithelial cell barrier and activating mucosal macrophages, which, in turn, causes an inflammatory response [3]. We pretreated animals with CBR (200 and $500 \mathrm{mg} / \mathrm{kg} /$ day) for 


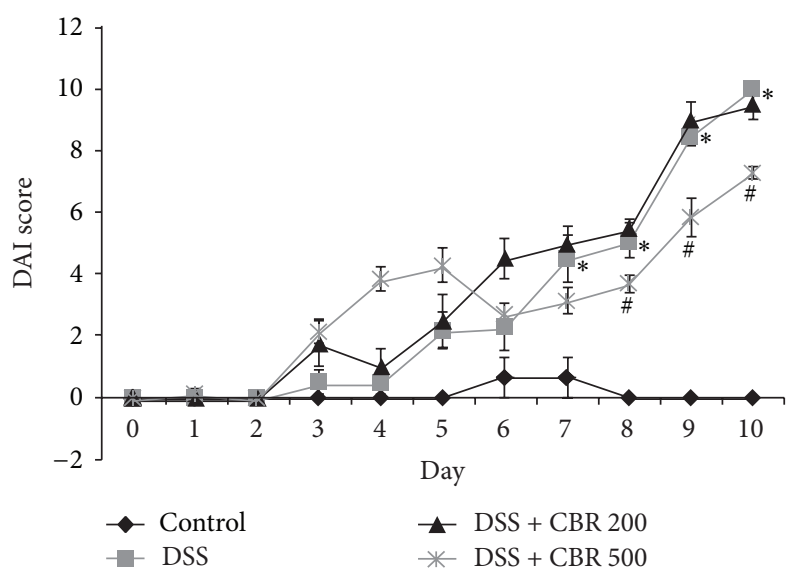

FIgure 5: Ameliorative effects of the CBR extract on the disease activity index (DAI) score. The DAI score was monitored daily. DAI was significantly lower in CBR+3.5\% DSS compared with 3.5\% DSS. Data are expressed as the mean \pm S.E. $(n=6$ per group $)\left({ }^{*} P<0.05\right.$ versus control; ${ }^{\#} P<0.05$ versus DSS; two-way ANOVA followed by a post hoc analysis). DSS dextran sulfate sodium; CBR AC grown on germinated brown rice.
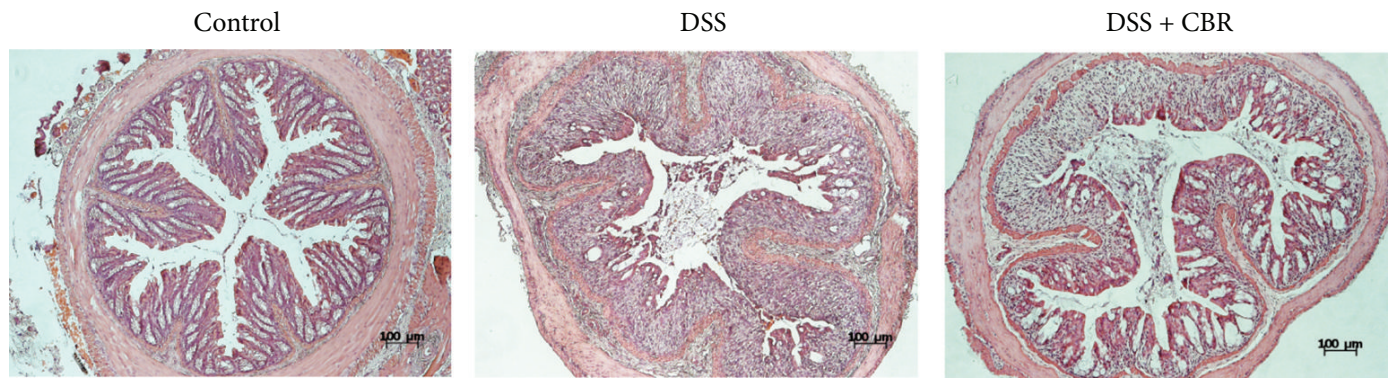

(a)

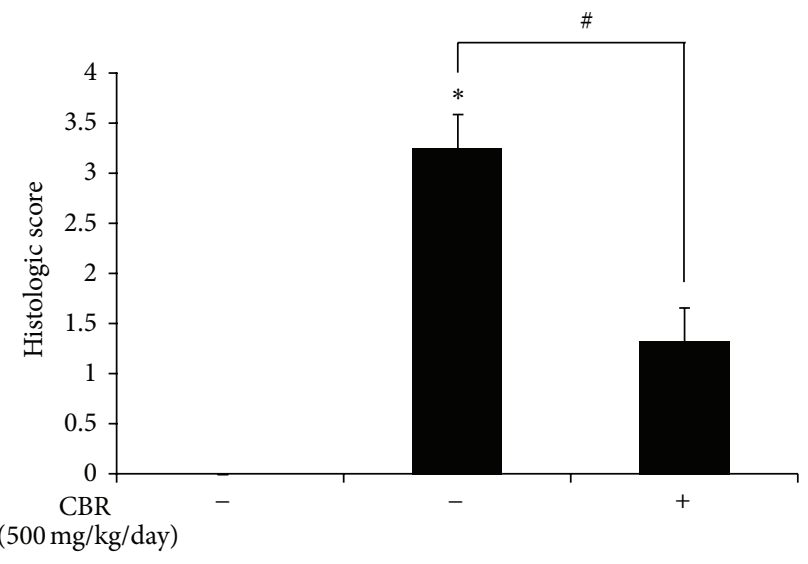

DSS

(b)

Figure 6: Effect of CBR extract on colonic histological changes. (a) Representative histological findings in mice with dextran-sodiumsulfate-(DSS-) induced colitis. Representative sections of colon tissues from normal mice administered with drinking water (control), mice administered with DSS-induced colitis (DSS), and mice coadministered with DSS and CBR extract (DSS+CBR). Histological changes were determined by H\&E staining. Scale bar $=100 \mu \mathrm{m}$. Original magnification: 100x. Protein expression of iNOS and COX-2 was analyzed by western blot analysis and quantified by densitometric analysis. (b) Histological score was measured. (c) Histologic score of colitis induced by DSS. Data are expressed as mean \pm S.E ( $n=6$ per group). ( ${ }^{*} P<0.05$ versus control; ${ }^{*} P<0.05$ versus DSS.) DSS: dextran sulfate sodium; CBR: Antrodia camphorata grown on germinated brown rice. 


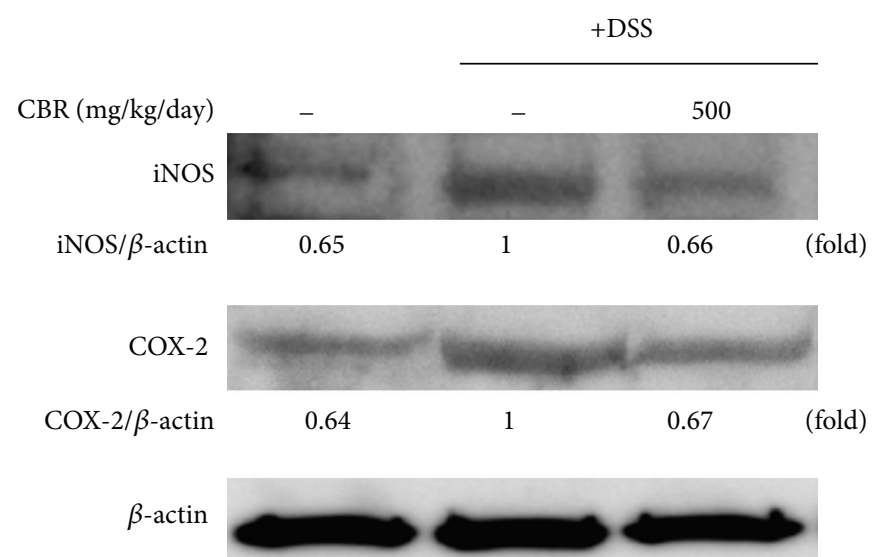

(a)

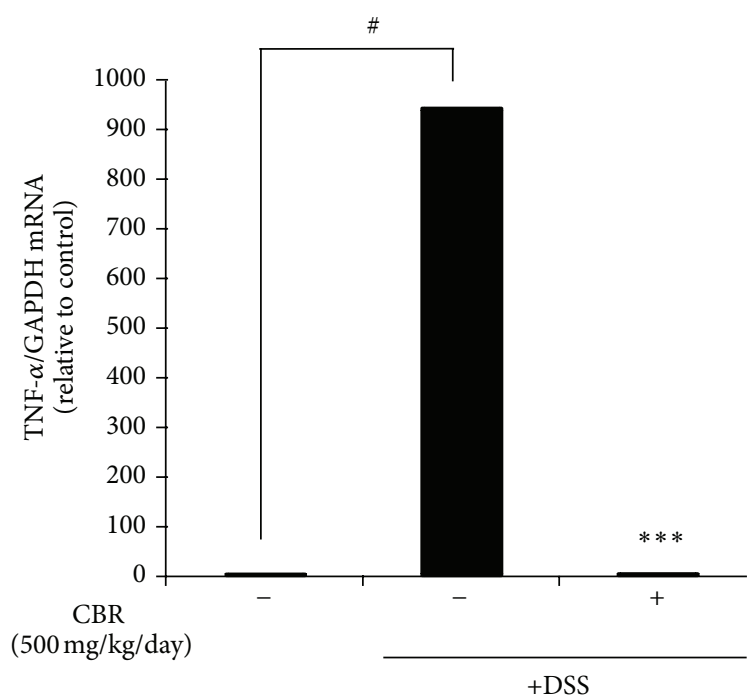

(b)

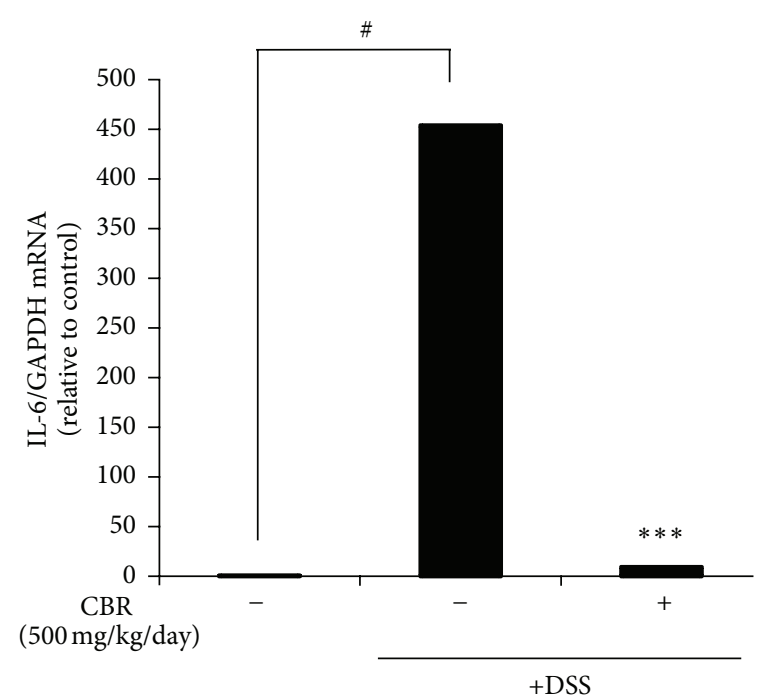

(c)

FIgURE 7: Effect of the CBR extract on the DSS-induced iNOS and COX-2 protein expression and TNF- $\alpha$ and IL-6 mRNA expression levels. (a) Immunoblotting analysis of iNOS and COX-2. Representative colon tissue lysates from normal mice administered with drinking water (control), mice administered with DSS-induced colitis (DSS), and mice coadministered with DSS and CBR extract (DSS+CBR) (left to right lane). Protein expression of iNOS and COX-2 was analyzed by western blot analysis and quantified by densitometric analysis. (b, c) TNF- $\alpha$ and IL- 6 mRNA expression levels of colon tissues were analyzed by RT-PCR and determined by quantitative $\Delta \triangle \mathrm{C}_{\mathrm{T}}$ RT-PCR by using GAPDH mRNA as the internal control. Data represent the mean \pm standard error (S.E.) of 3 independent experiments. A one-way ANOVA was used for comparisons of multiple group means followed by Dunnett's $t$-test $\left({ }^{\#} P<0.05\right.$ versus control; ${ }^{* * *} P<0.001$ versus DSS).

2 days before DSS was administered. This study design may be helpful for patients in the acute phase of UC in that the prophylactic administration of CBR may be recommended.

The protective effects of the CBR extract on DSSinduced colitis were assessed by macroscopic and histological analyses. Improved characteristic symptoms of IBD (e.g., diarrhea, bloody stools, abdominal pain, and weight loss) and histopathological characteristics (e.g., crypt abscesses, crypt distortion, ulceration, and the infiltration of large numbers of neutrophils, monocytes, and lymphocytes) were observed in the CBR-fed groups (Figure 4). At $500 \mathrm{mg} / \mathrm{kg} / \mathrm{day}$ of the CBR EtOH extract, the severity of DSS-induced acute colitis symptoms was markedly reduced. This was evidenced by a decrease in weight loss, DAI score, and histopathological scores $(P<0.05$; Figures 5 and 6$)$. According to the interspecies dosage scaling calculation, the human equivalent dose of the CBR EtOH fraction in our in vivo study was approximately $427.26 \mathrm{mg}$ for an adult weighing $60 \mathrm{~kg}$; this dose is applicable in future clinical investigations.

Oxidative stress is a major cause of tissue damage and inflammation [1]. Sustained, high levels of NO production, especially when mediated by iNOS in the colon, play a role in the pathology of IBD [26-28]. Several synthetic iNOS inhibitors were effective in suppressing DSS-induced colitis symptoms in mice [26-28]. Marked elevated levels of $\mathrm{PGE}_{2}$ and COX-2 were also observed during inflammation, including DSS-induced colonic injury [29]. Our data demonstrated that CBR extracts decreased the levels of iNOS and COX-2 


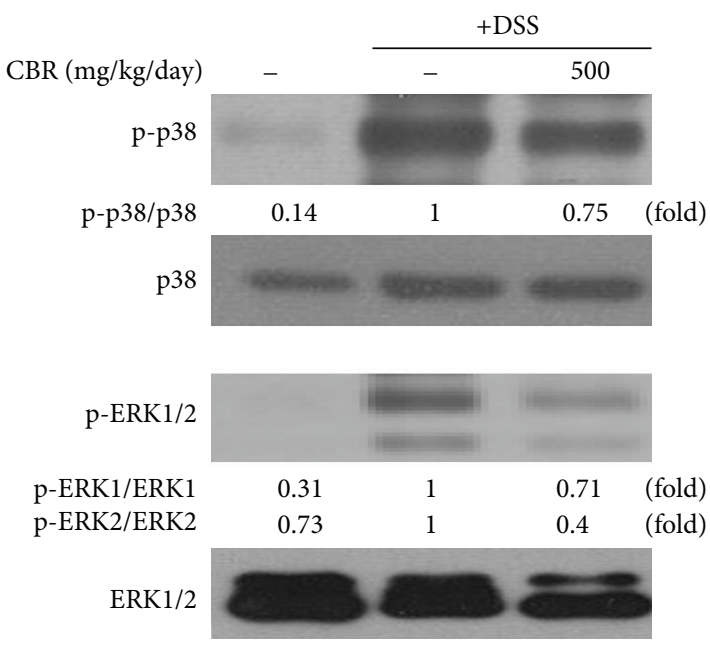

(a)
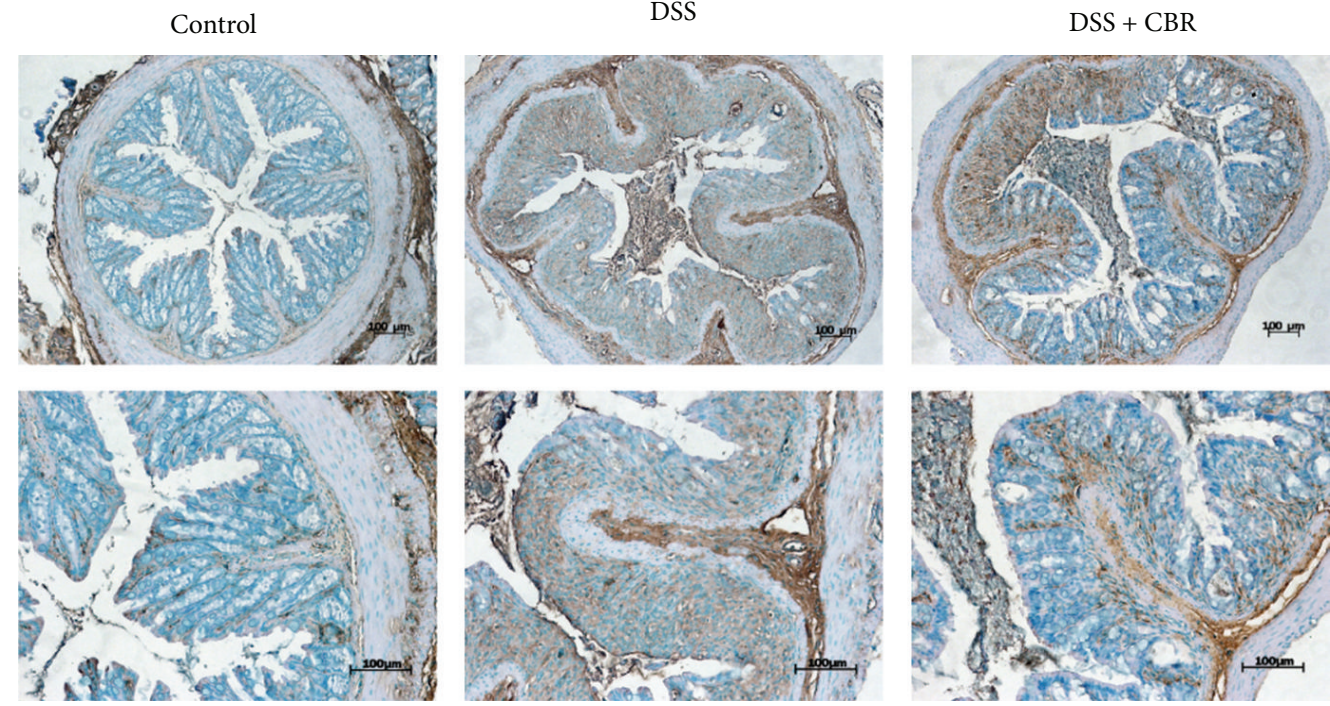

(b)

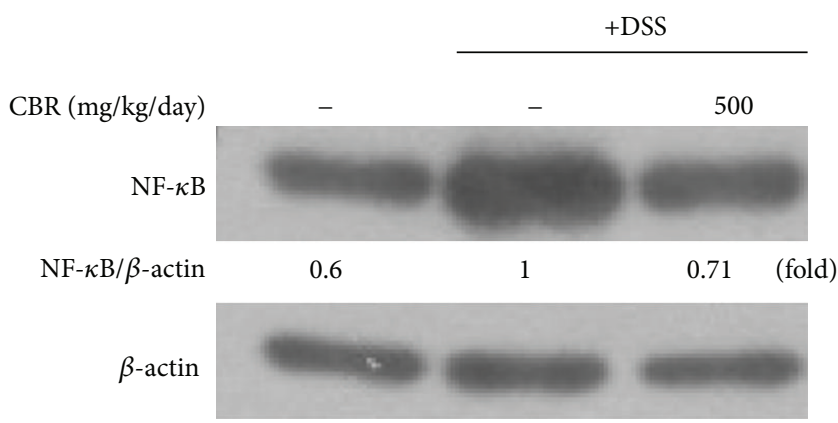

(c)

FIGURE 8: Effect of the CBR extract on the DSS-induced MAPK and NF- $\kappa$ B protein expression. (a) Immunoblotting analysis of phosphorylated MAPKs. Representative colon tissue lysates from normal mice administered with drinking water (control), mice administered with DSSinduced colitis (DSS), and mice coadministered with DSS and CBR extract (DSS + CBR) (from left to right). Protein expression of MAPK and NF- $\kappa \mathrm{B}$ was analyzed by western blot analysis and quantified by densitometric analysis. (b) The immunohistochemical analysis was used to monitor the protein expression of NF- $\kappa \mathrm{B}$. Scale bar $=100 \mu \mathrm{m}$. Original magnification: 100x and 200x (top and bottom panels, resp.). (c) Immunoblotting analysis of NF- $\kappa \mathrm{B}$. 
in the colonic tissues of DSS-administered mice. This finding suggests that the CBR extract acts as an iNOS and COX2 inhibitor, thus protecting the colon from DSS-induced tissue injury and inflammation by reducing nitrosative stress. It was reported that high levels of proinflammatory cytokines, including TNF- $\alpha$ and IL-6, were detected in DSSadministered mice. TNF- $\alpha$ damages the epithelial barrier of the colon and induces apoptotic death of epithelial cells in the colon [1]. Consistent with the findings from a previous study, the CBR extract significantly attenuated the levels of TNF- $\alpha$ and IL-6 mRNA expression in the colonic tissues of mice with DSS-induced acute colitis (Figure 7).

Recent experiments showed the importance of $\mathrm{p} 38$ in UC, where the use of p38 and ERK inhibitors abrogated colitis $[30,31]$. Moreover, a recent study demonstrated that it can be effective for treating human IBD. p38 is known to regulate several target genes that ultimately control infiltration of monocytic cells, acute intestinal inflammation, intestinal electrolyte and water secretion, and cytokine production. Furthermore, it upregulates COX-2 expression in intestinal epithelial cells [30]. Growing evidence indicated that the inhibition of NF- $\kappa$ B activity (e.g., a direct blockade of RelA (p65), suppression of $\mathrm{I} \kappa \mathrm{B} \alpha$ degradation, or IKK $\beta$ activity) may alleviate the severity of intestinal inflammation [5]. Numerous natural anti-inflammatory products (e.g., Cissus quadrangularis, Taraxacum officinale, and Sanguisorba officinalis) [32, 33] have been reported as NF- $\kappa \mathrm{B}$ inhibitors, which can be regarded as potential anti-inflammatory drug candidates. Indeed, many recent studies have focused on developing novel anti-inflammatory drugs targeted to regulate NF- $\kappa \mathrm{B}$ activity [34]. In agreement with the in vitro study, the CBR extract inhibited phosphorylation of p38 and ERK1/2 as well as the protein level of the NF- $\kappa$ B p 65 subunit (Figure 8). Therefore, CBR may possess anti-inflammatory activities through the modulation of the NF- $\kappa \mathrm{B}$ signaling pathway and its upstream signaling enzymes, which could be a primary target for the treatment of IBD. Total flavonoid content in the CBR extract was determined to be $0.18 \%$, as determined by a previously published method [35] (data not shown). Further studies will explore the effects of compounds derived from the CBR extract on the acute colitis model.

\section{Conclusion}

In summary, this study showed, for the first time, that the CBR extract significantly reduces DSS-induced colitis symptoms through the prevention of body weight loss and colon shortness and decreasing the DAI scores. The protective effects of CBR extracts may be attributed to a significant reduction in the levels of iNOS and COX-2 proteins and TNF$\alpha$ and IL- 6 production. The inhibitory activity of the CBR extract against these inflammatory mediators may be due to the regulation of the NF- $\kappa$ B and MAPK signaling pathways. These results suggest that the CBR extract might be a potent anti-inflammatory candidate for preventing IBDs.

\section{Conflict of Interests}

The authors have nothing to disclose.

\section{Acknowledgments}

This work was supported by the SMART Research Professor Program of Konkuk University, Seoul, Republic of Korea. The authors would like to thank Ms. JungWon Choi and Sun mi Kim for technical assistance.

\section{References}

[1] A. N. Ananthakrishnan, E. L. McGinley, D. G. Binion, and K. Saeian, "A nationwide analysis of changes in severity and outcomes of inflammatory bowel disease hospitalizations," Journal of Gastrointestinal Surgery, vol. 15, no. 2, pp. 267-276, 2011.

[2] Y. J. Feng and Y. Y. Li, "The role of p38 mitogen-activated protein kinase in the pathogenesis of inflammatory bowel disease," Journal of Digestive Diseases, vol. 12, no. 5, pp. 327-332, 2011.

[3] E. S. Han, J. Y. Oh, and H. Park, "Cordyceps militaris extract suppresses dextran sodium sulfate-induced acute colitis in mice and production of inflammatory mediators from macrophages and mast cells," Journal of Ethnopharmacology, vol. 134, no. 3, pp. 703-710, 2011.

[4] S. Bae, S. Choi, K. Kim et al., "Effects of genetic polymorphisms of MDR1, FMO3 and CYP1A2 on susceptibility to colorectal cancer in Koreans," Cancer Science, vol. 97, no. 8, pp. 774-779, 2006.

[5] M. F. Neurath, S. Pettersson, K. Meyer zum Buschenfelde, and W. Strober, "Local administration of antisense phosphorothioate oligonucleotides to the p65 subunit of NF- $\kappa \mathrm{B}$ abrogates established experimental colitis in mice," Nature Medicine, vol. 2, no. 9, pp. 998-1004, 1996.

[6] S. Chae, L. Eckmann, Y. Miyamoto, C. Pothoulakis, M. Karin, and M. F. Kagnoff, "Epithelial cell $\mathrm{I} \kappa \mathrm{B}$-kinase $\beta$ has an important protective role in Clostridium difficile toxin A-induced mucosal injury," Journal of Immunology, vol. 177, no. 2, pp. 1214-1220, 2006.

[7] G. Huang, S. Huang, S. Lin et al., "Analgesic effects and the mechanisms of anti-inflammation of ergostatrien- $3 \beta$-ol from antrodia camphorata submerged whole broth in mice," Journal of Agricultural and Food Chemistry, vol. 58, no. 12, pp. 74457452, 2010.

[8] Z. Ao, Z. Xu, Z. Lu, H. Xu, X. Zhang, and W. Dou, "Niuchangchih (Antrodia camphorata) and its potential in treating liver diseases," Journal of Ethnopharmacology, vol. 121, no. 2, pp. 194-212, 2009.

[9] M. Geethangili and Y. Tzeng, "Review of pharmacological effects of antrodia camphorata and its bioactive compounds," Evidence-Based Complementary and Alternative Medicine, vol. 2011, Article ID 212641, 17 pages, 2011.

[10] Y. Hsieh, Y. K. Rao, C. Wu et al., "Methyl antcinate a from antrodia camphorata induces apoptosis in human liver cancer cells through oxidant-mediated cofilin- and bax-triggered mitochondrial pathway," Chemical Research in Toxicology, vol. 23, no. 7, pp. 1256-1267, 2010.

[11] S. Chien, M. Chen, H. Kuo, Y. Tsai, B. Lin, and Y. Kuo, "Antiinflammatory activities of new succinic and maleic derivatives from the fruiting body of Antrodia camphorata, Journal of Agricultural and Food Chemistry, vol. 56, no. 16, pp. 7017-7022, 2008.

[12] J. Chang, Y. Lee, L. Hung et al., "An extract of antrodia camphorata mycelia attenuates the progression of nephritis in systemic lupus erythematosus-prone NZB/W F1 mice," Evidence-Based 
Complementary and Alternative Medicine, vol. 2011, Article ID 465894, 7 pages, 2011.

[13] M. Song, D. Park, and H. Park, "Antrodia camphorata grown on germinated brown rice suppresses melanoma cell proliferation by inducing apoptosis and cell differentiation and tumor growth," Evidence-Based Complementary and Alternative Medicine, vol. 2013, Article ID 321096, 9 pages, 2013.

[14] D. K. Park, T. Hayashi, and H. J. Park, "Arabinogalactan-type polysaccharides (APS) from Cordyceps militaris grown on germinated soybeans (GSC) induces innate immune activity of THP-1 monocytes through promoting their macrophage differentiation and macrophage activity," Food Science and Biotechnology, vol. 21, no. 5, pp. 1501-1506, 2012.

[15] H. Park, E. S. Han, D. K. Park, C. Lee, and K. W. Lee, "An extract of Phellinus linteus grown on germinated brown rice inhibits inflammation markers in RAW264.7 macrophages by suppressing inflammatory cytokines, chemokines, and mediators and up-regulating antioxidant activity," Journal of Medicinal Food, vol. 13, no. 6, pp. 1468-1477, 2010.

[16] Y. Azuma, K. Nishiyama, Y. Matsuo et al., "PPAR $\alpha$ contributes to colonic protection in mice with DSS-induced colitis," International Immunopharmacology, vol. 10, no. 10, pp. 1261-1267, 2010.

[17] A. N. Ananthakrishnan, C. Hur, and J. R. Korzenik, "Certolizumab pegol compared to natalizumab in patients with moderate to severe crohn's disease: results of a decision analysis," Digestive Diseases and Sciences, vol. 57, no. 2, pp. 472-480, 2012.

[18] M. A. McGuckin, R. Eri, L. A. Simms, T. H. J. Florin, and G. Radford-Smith, "Intestinal barrier dysfunction in inflammatory bowel diseases," Inflammatory Bowel Diseases, vol. 15, no. 1, pp. 100-113, 2009.

[19] D. M. Mosser and J. P. Edwards, "Exploring the full spectrum of macrophage activation," Nature Reviews Immunology, vol. 8, no. 12, pp. 958-969, 2008.

[20] F. S. Laroux, K. P. Pavlick, I. N. Hines et al., "Role of nitric oxide in inflammation," Acta Physiologica Scandinavica, vol. 173, no. 1, pp. 113-118, 2001.

[21] H. B. Jijon, W. J. Panenka, K. L. Madsen, and H. G. Parsons, "MAP kinases contribute to IL- 8 secretion by intestinal epithelial cells via a posttranscriptional mechanism," American Journal of Physiology, vol. 283, no. 1, pp. C31-C41, 2002.

[22] M. Sánchez-Hidalgo, A. R. Martín, I. Villegas, and C. Alarcón de la Lastra, "Rosiglitazone, a PPAR $\gamma$ ligand, modulates signal transduction pathways during the development of acute TNBSinduced colitis in rats," European Journal of Pharmacology, vol. 562, no. 3, pp. 247-258, 2007.

[23] F. Scaldaferri, M. Sans, S. Vetrano et al., "The role of MAPK in governing lymphocyte adhesion to and migration across the microvasculature in inflammatory bowel disease," European Journal of Immunology, vol. 39, no. 1, pp. 290-300, 2009.

[24] Y. Chen, P. Cheng, C. Lin et al., "Polysaccharides from Antrodia camphorata mycelia extracts possess immunomodulatory activity and inhibits infection of Schistosoma mansoni," International Immunopharmacology, vol. 8, no. 3, pp. 458-467, 2008.

[25] M. S. Hayden and S. Ghosh, "Shared principles in NF- $\kappa$ B signaling," Cell, vol. 132, no. 3, pp. 344-362, 2008.

[26] K. Yasukawa, H. Tokuda, X. Tun, H. Utsumi, and K. Yamada, "The detrimental effect of nitric oxide on tissue is associated with inflammatory events in the vascular endothelium and neutrophils in mice with dextran sodium sulfate-induced colitis," Free Radical Research, vol. 46, no. 12, pp. 1427-1436, 2012.
[27] A. Y. Sklyarov, N. B. Panasyuk, and I. S. Fomenko, "Role of nitric oxide-synthase and cyclooxygenase/lipooxygenase systems in development of experimental ulcerative colitis," Journal of Physiology and Pharmacology, vol. 62, no. 1, pp. 65-73, 2011.

[28] C. N. Ercin, Z. Yesilova, A. Korkmaz, A. Ozcan, C. Oktenli, and A. Uygun, "The effect of iNOS inhibitors and hyperbaric oxygen treatment in a rat model of experimental colitis," Digestive Diseases and Sciences, vol. 54, no. 1, pp. 75-79, 2009.

[29] D. C. Montrose, N. A. Horelik, J. P. Madigan et al., "Antiinflammatory effects of freeze-dried black raspberry powder in ulcerative colitis," Carcinogenesis, vol. 32, no. 3, pp. 343-350, 2011.

[30] J. Chiou, A. T. H. Wu, W. Wang et al., "A preclinical evaluation of antrodia camphorata alcohol extracts in the treatment of nonsmall cell lung cancer using non-invasive molecular imaging," Evidence-Based Complementary and Alternative Medicine, vol. 2011, Article ID 914561, 12 pages, 2011.

[31] J. B. Seidelin, M. Coskun, B. Vainer, L. Riis, C. Soendergaard, and O. H. Nielsen, "ERK controls epithelial cell death receptor signalling and cellular FLICE-like inhibitory protein (c-FLIP) in ulcerative colitis," Journal of Molecular Medicine, 2013.

[32] J. Y. Han, J. Im, J. N. Choi et al., "Induction of IL-8 expression by Cordyceps militaris grown on germinated soybeans through lipid rafts formation and signaling pathways via ERK and JNK in A549 cells," Journal of Ethnopharmacology, vol. 127, no. 1, pp. 55-61, 2010.

[33] W. Seok Yang, J. Lee, T. Woong Kim et al., "Src/NF- $\kappa$ B-targeted inhibition of LPS-induced macrophage activation and dextran sodium sulphate-induced colitis by Archidendron clypearia methanol extract," Journal of Ethnopharmacology, vol. 142, no. 1, pp. 287-293, 2012.

[34] Y. A. Ivanenkov, K. V. Balakin, and Y. Lavrovsky, "Small molecule inhibitors of NF-kB and JAK/STAT signal transduction pathways as promising anti-inflammatory therapeutics," Mini-Reviews in Medicinal Chemistry, vol. 11, no. 1, pp. 55-78, 2011.

[35] J. N. Choi, J. Kim, M. Y. Lee, D. K. Park, Y. Hong, and C. H. Lee, "Metabolomics revealed novel isoflavones and optimal cultivation time of cordyceps militaris fermentation," Journal of Agricultural and Food Chemistry, vol. 58, no. 7, pp. 4258-4267, 2010. 


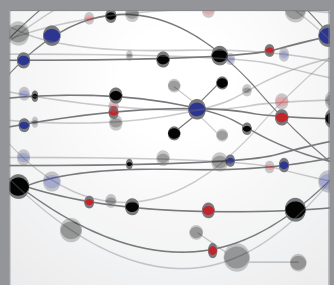

The Scientific World Journal
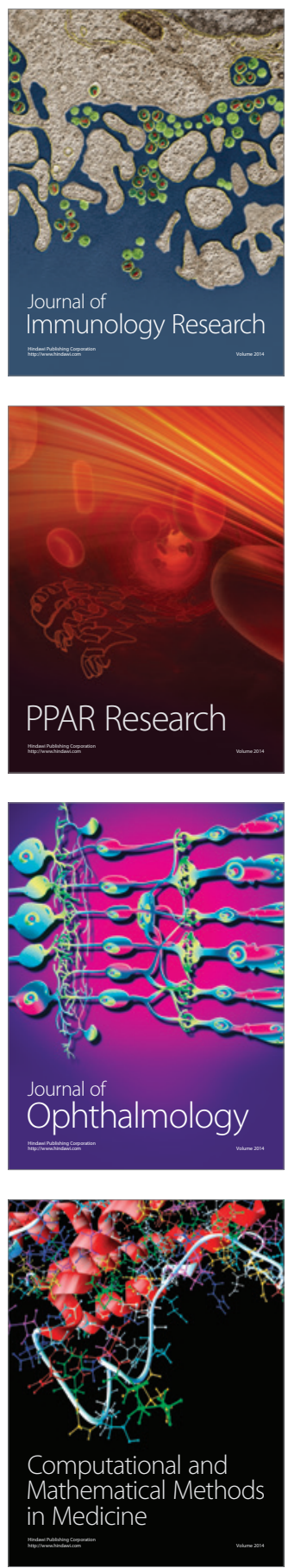

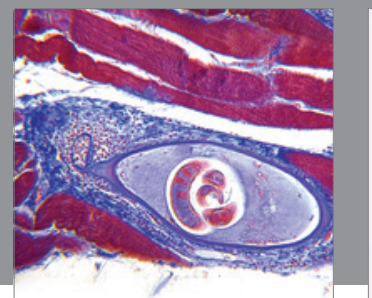

Gastroenterology

Research and Practice
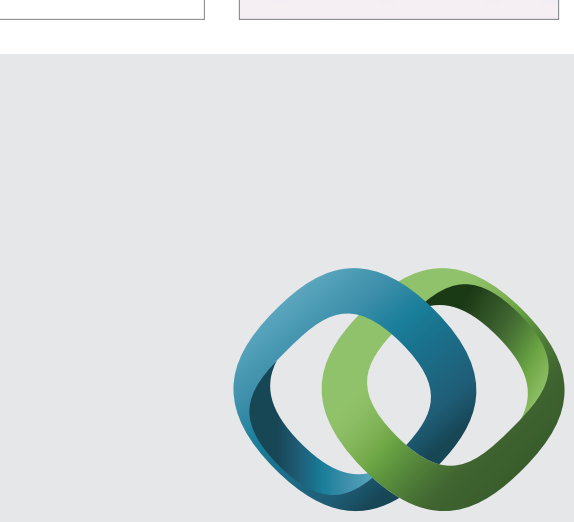

\section{Hindawi}

Submit your manuscripts at

http://www.hindawi.com
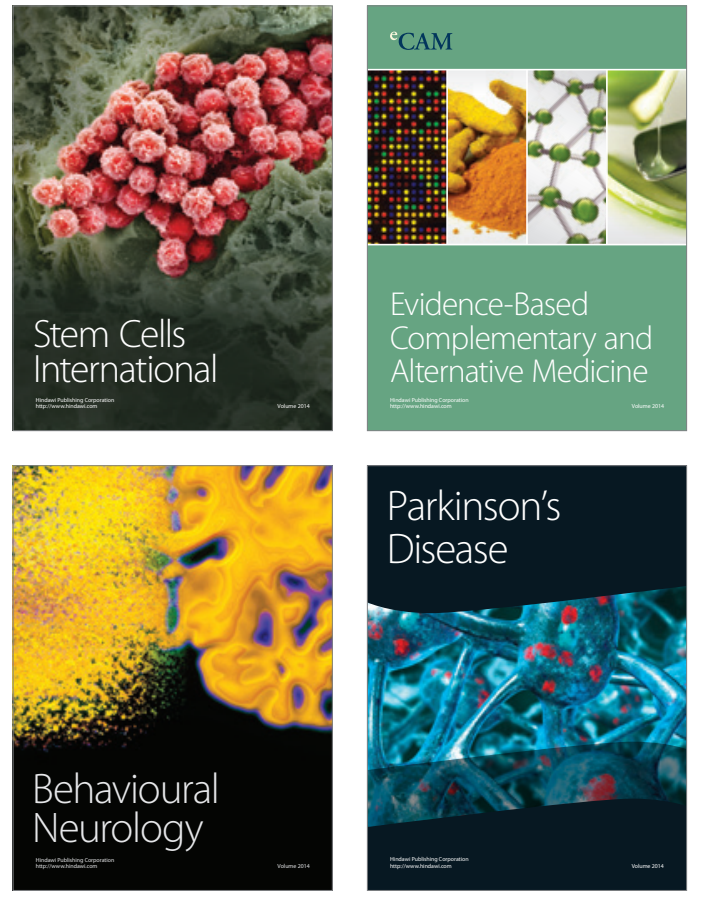
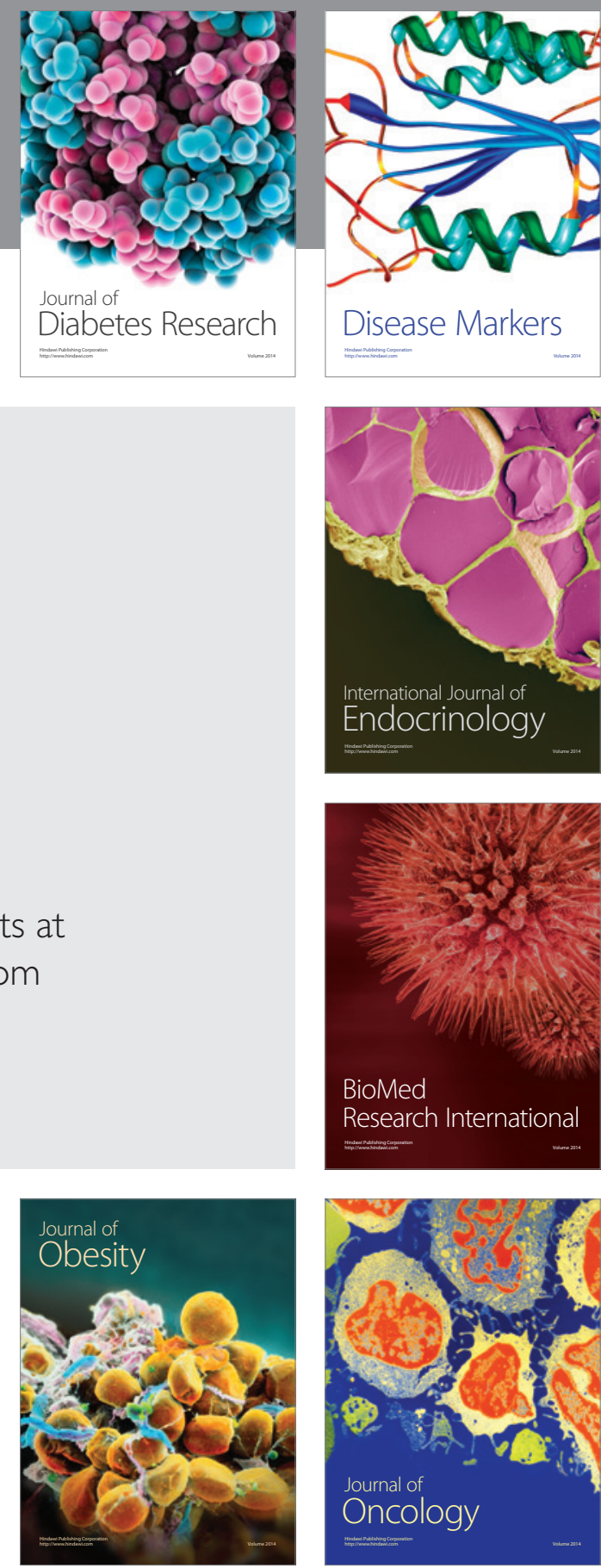

Disease Markers
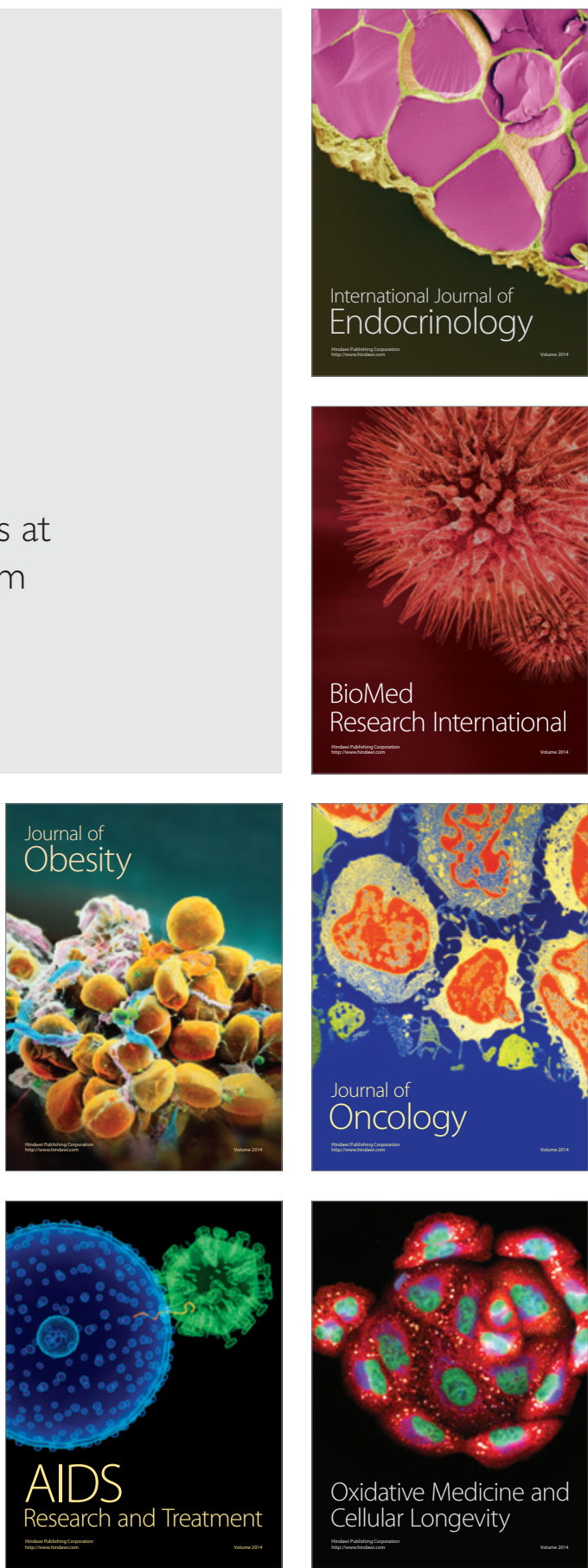